Universidade Tecnológica Federal do Paraná - UTFPR

Campus Ponta Grossa - Paraná - Brasil

ISSN: $1981-3686 /$ v. 05, n. $02:$ p. $542-549,2011$

D.O.I.: $10.3895 / \mathrm{S} 1981-36862011000200006$
Revista Brasileira de Tecnologia

Agroindustrial

\title{
PARÂMETROS DE QUALIDADE DE AMÊNDOAS DE CASTANHA DO BRASIL COMERCIALIZADAS EM RIO BRANCO - ACRE
}

\section{QUALITY PARAMETERS OF ALMOND CHESTNUT-OF-BRAZIL CONSUMED IN RIO BRANCO - ACRE}

\author{
Lilliane Maria de Oliveira Martins ${ }^{1}$, Williane Maria de Oliveira Martins ${ }^{2}$ \\ ${ }^{1}$ Instituto Federal do Acre- IFAC - Cruzeiro do Sul - Brasil, lilliane.martins@ifac.edu.br \\ ${ }^{2}$ Instituto Federal do Acre - UFAC - Cruzeiro do Sul - Brasil, williane.martins@ifac.edu.br
}

\begin{abstract}
Resumo
O presente estudo teve como objetivo avaliar a qualidade das amêndoas de castanha-do-brasil comercializadas e consumidas em Rio Branco- AC, através de parâmetros físicos, químicos e microbiológicos. $O$ estudo foi conduzido na Unidade Tecnológica de Alimentos/UTAL $e$ Laboratório de Fitopatologia da Universidade Federal do Acre/UFAC. Foram realizadas análises microbiológicas para a determinação de bactérias mesófilas, coliformes a $35^{\circ} \mathrm{C}$ e a $45^{\circ} \mathrm{C}$, bolores e leveduras, segundo Vanderzant e Splittstoesser (1992). As análises físico-químicas para a determinação do teor de umidade e rancidez das amostras de amêndoas foram realizadas utilizando os procedimentos contidos nas Normas Analíticas do Instituto Adolf Lutz (1985). A contagem de coliformes a $45{ }^{\circ} \mathrm{C}$ variou de $<3$ a $93 \mathrm{NMP} / \mathrm{g}$ para a Marca 1 e de $<3$ a $240 \mathrm{NMP} / \mathrm{g}$ para a Marca 2. Para os coliformes totais, os resultados obtidos variaram de <3 a $240 \mathrm{NMP} / \mathrm{g}$ para a Marca 1 e de $<3$ a 21 NMP/g para a Marca 2. A contagem de bactérias mesófilas variou de

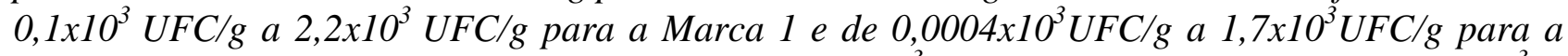

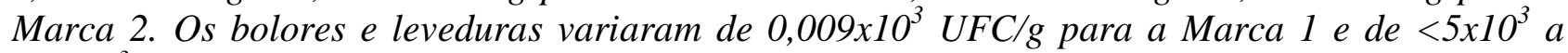
3,0x10 UFC/g para a Marca 2. As amêndoas de castanha-do-brasil apresentaram níveis de contaminação de coliformes a $45{ }^{\circ} \mathrm{C}$ dentro dos padrões da legislação. Os microrganismos encontrados, bactérias mesófilas, bolores, leveduras e coliformes totais indicam falhas no processamento, sinalizando higiene inadequada. Os resultados positivos de rancidez em algumas amostras indicam deficiência do sistema embalagem e armazenagem dos produtos, sinalizando higiene inadequada e necessidade de implementação de Boas Práticas de Fabricação (BPF) e Procedimentos Padrões de Higiene Operacional (PPHO).
\end{abstract}

Palavras-chave: amêndoa de castanha-do-brasil, coliformes, rancidez.

\section{Introdução}

A castanha-do-brasil (Bertholletia excelsa, H.B.K) é uma planta nativa da Amazônia e uma das mais importantes espécies de exploração extrativista. Árvore de grande porte podendo medir até $60 \mathrm{~m}$ de altura, com diâmetro de 100 a $180 \mathrm{~cm}$. Planta semidecídua, heliófila e social, pois 
encontra-se associada a outras espécies (DONADIO, 2002). É conhecida como castanha, castanha verdadeira, castanheiro, castanha-do-pará, castanha-do-maranhão e castanha-do-brasil.

A exploração de castanha-do-brasil tornou-se a principal atividade econômica na região amazônica desde o declínio da exploração de borracha, sustentando milhares de extrativistas e toda uma oligarquia decorrente desta riqueza (HOMMA, 2004). As castanheiras nativas iniciam a produção aos oito anos e atingem aos doze a produção normal. Em castanheiras enxertadas (gemas) a produção inicia-se com apenas 3,5 anos e a safra ocorre de janeiro a fevereiro e de abril a maio (SOUZA, 1984).

Cavalcante (1972) citado por Souza (1984) descreve o fruto como pixídio imperfeito, vulgarmente denominado de ouriço, esférico ou levemente depresso, com mesocarpo extremamente duro constituído de células pétreas; parte superior com uma região diferenciada; opérculo imergindo quando o fruto está bastante velho. O fruto é em cápsula, denominado de ouriço, cujo seu interior encontram-se sementes formadas por amêndoas brancas cobertas por uma película marrom; contendo em média de 15 a 24 sementes, angulosas com 4 a $7 \mathrm{~cm}$ de comprimento (DONADIO, 2002).

Tem participação na geração de divisas para o Brasil, cuja 95\% da produção é comercializada para o mercado internacional, devendo-se destinar também a agregar valor no mercado local de sua origem, através da sua transformação em ingredientes de alto valor alimentar, para aplicação no enriquecimento de alimentos, através de instalação de agroindústrias, gerando oportunidades de trabalho (SOUZA, 2003).

No Estado do Acre os maiores produtores de castanha-do-brasil são os municípios de Rio Branco, Xapuri e Sena Madureira, produzindo principalmente para o mercado externo. As perdas na comercialização dizem respeito, principalmente a qualidade das amêndoas comercializadas (SOUZA, 1984).

A produção depende exclusivamente de solicitação de comprador externo e é determinada pelo mercado internacional. Não é um produto básico na alimentação das populações dos países que a importam, seu consumo é irregular, sujeito as oscilações, e portanto, também irregular é a sua produção (SOUZA, 1984). Segundo a mesma autora, a maior parte da castanha exportada é destinada a confeitaria, onde é misturada com outros produtos similares a guiza, uma vez que seu sabor especial prevalece na confecção de doces finos, principalmente á base de chocolate. Entretanto, apesar da castanheira fornecer diversos produtos e subprodutos, as amêndoas apresentam maior valor econômico por serem utilizadas de muitas maneiras, ao natural, produção de óleos, leite, farinha de castanha, além de apresentar alto valor nutritivo, pela alta qualidade de seus aminoácidos (SOUZA, 2003). 
As amêndoas são ricas em bário, bromo, cobalto, césio, magnésio, níquel e, principalmente em selênio, sendo os três primeiros com níveis maiores do que em outras nozes. Os seus principais ácidos graxos são o palmítico, o oléico e o linoléico (SOUZA, 1984; DONADIO, 2002). Segundo Costa (1991) a castanha-do-brasil é rica em vitaminas A, B e C e altamente energética, pois fornece $751,6 \mathrm{cal} / 100 \mathrm{~g}$.

A qualidade da castanha-do-brasil, aliada a reduzida produção que e destinada ao mercado interno, fazem com que o seu consumo fique restrito a classe de renda alta e que a maior parte seja destinada a industrialização de doces finos, por mais útil rendimento (SOUZA, 1984). O fato do transporte das castanhas até as usinas beneficiadoras coincidir com a época das chuvas é um fator desvantajoso, pois isto leva ao armazenamento das castanhas com alto percentual de umidade, oferecendo condições ideais ao desenvolvimento de bactérias e fungos, acelerando o processo de deterioração (COSTA, 1991), principalmente pelo perigo químico das aflatoxinas, metabólitos tóxicos ao homem e animais que podem ser produzidas por fungos dos gêneros Aspergillus e Penicillum (SOUZA, 2003).

Segundo Frank et al. (1980) citado por Costa (1991) os fungos produtores de aflatoxinas podem penetrar através da casca das castanhas em ambientes com uma umidade relativa acima de $75 \%$ e contaminar as sementes. Segundo os autores, o risco de contaminação por aflatoxinas é bem menor em castanhas descascadas. Os microrganismos presentes na castanha-do-brasil causam alterações químicas indesejáveis, é a deterioração microbiológica. Essa deterioração resulta em alterações de cor, odor, sabor, textura e aspecto. Os microrganismos maléficos podem representar um risco à saúde, podendo afetar a saúde do homem e animais (LEITE, 2002; SOUZA, 2003).

O beneficiamento da castanha-do-brasil é um processo que envolve muita manipulação e portanto exige a atenção e higienização minunciosa para obtenção de um produto com qualidade microbiológica garantida (SOUZA, 2002). Castanhas contaminadas podem causar intoxicações e riscos significativos à saúde humana (LEITE, 2002). Dentro deste contexto, o presente trabalho tem como objetivo avaliar os parâmetros físico-químicos e microbiológicos de amêndoas de castanhado-brasil comercializadas em Rio Branco - Acre.

\section{Material e Métodos}

Para analisar a qualidade das amêndoas consumidas no comércio local, foram coletadas 05 amostras de amêndoas de castanha-do-brasil, pertencentes a diferentes lotes, das 02 principais marcas comercializadas nas 02 maiores redes de supermercados da cidade de Rio Branco - Acre, aqui representadas por Marca 1 e Marca 2. As coletas foram realizadas individualmente em suas embalagens comerciais originais, fechadas e intactas, contendo 200 e $500 \mathrm{~g}$, respectivamente, e 
encaminhadas a Unidade Tecnológica de Alimentos/UTAL da Universidade Federal do Acre/UFAC para realização das análises.

Foram realizadas análises microbiológicas para a determinação da contagem de bactérias mesófilas e de bolores e leveduras segundo o método de contagem de microrganismos em placas em UFC/g, e para a determinação de coliformes totais a $35{ }^{\circ} \mathrm{C}$ e coliformes a $45{ }^{\circ} \mathrm{C}$ (termotolerantes) utilizou-se o Método do Número Mais Provável (NMP/g), conforme Vanderzant e Splittstoesser (1992).

Foram pesados e separados 25 gramas de cada amostra para realizar as análises citadas, através do preparo das diluições decimais $\left(10^{-1} ; 10^{-2} ; 10^{-3}\right)$ utilizando solução salina estéril. Para Contagem Padrão em Placa (CPP) de bactérias Mesófilas em UFC/g adotou-se o método de plaqueteamento em profundidade, de cada diluição, utilizando-se o Agar Padrão para Contagem (PCA), com incubação a $35^{\circ} \mathrm{C}$ por $48 \mathrm{~h}$.

Para a contagem de bolores e leveduras em UFC/g empregou-se o método de plaqueteamento em superfície, para cada diluição, utilizando o Ágar Dicloran Rosa de Bengala Cloranfenicol (DRBC), com incubação a $25^{\circ} \mathrm{C}$ durante 5 dias.

$\mathrm{Na}$ determinação do Número Mais Provável (NMP/g) de Coliformes totais a $35{ }^{\circ} \mathrm{C}$ e termotolerantes a $45^{\circ} \mathrm{C}$ utilizou-se a técnica dos tubos múltiplos, com três séries de três tubos em cada diluição $\left(10^{-1} ; 10^{-2} ; 10^{-3}\right)$, empregando-se como meio presuntivo o caldo lauril sulfato triptose com incubação a $35{ }^{\circ} \mathrm{C}$ durante 48 horas. Após leitura, os tubos positivos (que apresentaram produção de gás), foram repicados para caldo EC com incubação a 44,5 ${ }^{\circ} \mathrm{C}$ em banho-maria, por 24 horas, para prova confirmativa de coliformes termotolerantes. A determinação do NMP/g de coliformes foi realizada com o auxílio da Tabela de Hoskins.

Para a determinação de análises físico-químicas foram trituradas amostras de cada marca de amêndoa de castanha-do-brasil para a determinação dos teores de umidade e rancidez, seguindo os procedimentos contidos nas Normas Analíticas do Instituto Adolf Lutz (1985).

\section{Resultados e Discussão}

Os resultados obtidos através de análises microbiológicas realizadas em triplicatas para coliformes totais a $35{ }^{\circ} \mathrm{C}$ e coliformes a $45{ }^{\circ} \mathrm{C}$ (termotolerantes), em NMP/g, bactérias mesófilas e bolores e leveduras em UFC/g estão apresentados nas Tabelas 1 e 2.

De acordo com os resultados da Tabela 1, observa-se que na marca 1 existe uma contaminação das amêndoas por coliformes totais e termotolerantes, porém com valores dentro dos padrões que estabelece a Resolução RDC $\mathrm{N}{ }^{\circ} 12$ de 02 de Janeiro de 2001 da ANVISA do Ministério da Saúde (BRASIL, 2001). Porém, na marca 2 a contaminação por estes microrganismos 
foi bem menor, com ausência na amostra 5 e com valores muito baixo nas demais, sendo a sua qualidade microbiológica melhor do que a marca 1.

Tabela 1 - Resultado de coliformes totais a $35^{\circ} \mathrm{C}$ e coliformes a $45^{\circ} \mathrm{C}$ (termotolerantes) das amostras de amêndoas de castanha-do-brasil coletadas nos supermercados de Rio Branco - Ac

\begin{tabular}{|c|c|c|c|}
\hline \multirow[b]{2}{*}{ Amostras } & \multirow[b]{2}{*}{ Coletas } & \multicolumn{2}{|c|}{ Determinações } \\
\hline & & $\begin{array}{c}\text { Coliformes totais a } 35^{\circ} \mathrm{C} \mathrm{em} \\
\text { NMP/g }\end{array}$ & $\begin{array}{c}\text { Coliformes a } 45^{\circ} \mathrm{C} \\
\text { em NMP/g }\end{array}$ \\
\hline \multirow{5}{*}{ Marca 1} & 1 & $<3$ & $<3$ \\
\hline & 2 & 93 & 93 \\
\hline & 3 & 240 & 43 \\
\hline & 4 & 240 & 21 \\
\hline & 5 & 93 & 20 \\
\hline \multirow{5}{*}{ Marca 2} & 1 & $<3$ & $<3$ \\
\hline & 2 & 21 & 15 \\
\hline & 3 & $<3$ & $<3$ \\
\hline & 4 & $<3$ & $<3$ \\
\hline & 5 & Ausente & Ausente \\
\hline
\end{tabular}

Os coliformes fecais são indicadores de contaminação fecal. Sua presença indica possível contaminação fecal . As presenças de bactérias mesófilas e bolores e leveduras indicam condições higiênicas inadequadas durante uma ou mais fases do processamento, especialmente pela manipulação sem os cuidados higiênicos necessários.

$\mathrm{Na}$ qualidade microbiológica devem ser considerados os aspectos econômicos, pois o alimento contaminado e/ou deteriorado leva a grandes perdas econômicas e de saúde pública, podendo ser um agente de toxi-infecção alimentar.

As castanhas-do-brasil podem ser atacadas por bolores ainda na árvore, no armazenamento e no transporte para as usinas de processamento, provocando sua deterioração (Frank, 1981 citado por Souza, 2002). Os resultados encontrados na Tabela 2 sinalizam que houve falhas no processamento de beneficiamento das amêndoas, especialmente aplicação de condições higiênicas inadequadas.

Tabela 2 - Resultado das pesquisas de bolores e leveduras e bactérias mesófilas das amostras de amêndoas coletadas nos supermercados locais

\begin{tabular}{cccc}
\hline \multirow{2}{*}{$\mathrm{R}^{\text {Amostras }}$} & Coletas & $\begin{array}{c}\text { Detorminações } \\
\text { Bactérias Mesófilas } \\
\text { UFC Leveduras }\end{array}$ & $\begin{array}{c}\text { U.g } \\
\text { UFC }\end{array}$ \\
\hline \multirow{3}{*}{ Marca 1 } & 1 & $0,009 \times 10^{3}$ & $1,3 \times 10^{3}$ \\
& 2 & $0,075 \times 10^{3}$ & $2,2 \times 10^{3}$ \\
& 3 & $2,0 \times 10^{3}$ & $0,10 \times 10^{3}$ \\
& 4 & $0,55 \times 10^{3}$ & $0,10 \times 10^{3}$ \\
Marca 2 & 5 & - & $1,65 \times 10^{3}$ \\
& 1 & $<5 \times 10^{3}$ & $1,7 \times 10^{3}$ \\
& 2 & $1,4 \times 10^{3}$ & $1,2 \times 10^{3}$ \\
& 3 & $0,5 \times 10^{3}$ & $0,004 \times 10^{3}$ \\
& 4 & $3,0 \times 10^{3}$ & $0,3 \times 10^{3}$ \\
\hline
\end{tabular}


Recomenda-se maior rigor nas operacionalizações dos sistemas de boas práticas agrícolas, de fabricação de higiene e analises de perigo e pontos críticos de controle para que possa ser adotado as medidas de correções visando a produção de um produto de maior qualidade e seguro a saúde dos consumidores.

Os resultados das análises físico-químicas de umidade e rancidez das amostras de amêndoas de castanha-do-brasil das marcas 1 e 2 estão apresentadas na Tabela 3.

Tabela 3 - Resultados das análises físico-químicas de umidade e rancidez das amostras de amêndoas de castanha-dobrasil das marcas 1 e 2

\begin{tabular}{|c|c|c|c|}
\hline \multirow[b]{2}{*}{ Amostras } & \multirow[b]{2}{*}{ Coletas } & \multicolumn{2}{|c|}{ Determinações } \\
\hline & & Umidade $(\%)$ & Rancidez \\
\hline \multirow{5}{*}{ Marca 1} & 1 & 1,66 & Negativo \\
\hline & 2 & - & Negativo \\
\hline & 3 & 2,05 & Positivo \\
\hline & 4 & 1,24 & Positivo \\
\hline & 5 & 0,80 & Positivo \\
\hline \multirow{5}{*}{ Marca 2} & 1 & 1,01 & Positivo \\
\hline & 2 & 1,21 & Positivo \\
\hline & 3 & 1,11 & Positivo \\
\hline & 4 & 3,07 & Positivo \\
\hline & 5 & 1,32 & Positivo \\
\hline
\end{tabular}

Observa-se que os percentuais de umidade encontrados estão muito baixos, o que interfere, favorecendo a deterioração oxidativa das amêndoas, estando os valores dentro do limite para a positividade deste tipo de deterioração oxidativa. Os resultados de rancidez obtidos, corroboram com os resultados da baixa umidade encontrada e indicaram que todas as amostras coletadas da marca 2 estavam rançosas, parâmetro que revela a qualidade inadequada do produto.

Nas análises físico-químicas, apresentadas na Tabela 3, a ocorrência de rancidez em todas as amostras analisadas da marca 2, sugere ou amêndoas passadas (velhas) de safra passada ou a ocorrência de falhas e/ou ausência de branqueamento e/ou no sistema de embalagem e estocagem dos produtos. Este parâmetro causa perdas na qualidade orgnoléptica, química e econômica das amêndoas de castanha-do-brasil bem como de qualquer outro alimento.

A identificação de falhas no processamento, embalagem e armazenamento do produto é importante para eliminar, prevenir ou reduzir os riscos de contaminação, possibilitando a produção de um produto com qualidade e seguro a saúde do consumidor.

\section{Conclusão}

As amêndoas de castanha-do-brasil apresentaram níveis de contaminação de coliformes a $45^{\circ} \mathrm{C}$ dentro dos padrões da legislação. Os microrganismos encontrados, bactérias mesófilas, 
bolores e leveduras e coliformes termotolerantes e totais indicam falhas no processamento, mesmo com os níveis considerados toleráveis para coliformes, o que reflete higiene inadequada.

Os resultados positivos de rancidez, na maioria das amostras indicam deficiência do sistema embalagem e armazenamento dos produtos. Os percentuais de umidade encontrados foram muito baixos, o que favorece a rancidez oxidativa.

Recomenda-se a implantação dos sistemas boas práticas de fabricação (BPF), procedimentos padrões de higiene operacional (PPHO) e análises de perigos e pontos críticos de controle (APPCC) nas usinas de beneficiamento de amêndoa de castanha-do-brasil visando à obtenção de um produto seguro ao mercado consumidor.

\begin{abstract}
The objective of this work was to evaluate the quality of the almond nut Brazil-marketed and consumed in Rio Branco-AC, through physical, parameters and microbiological contaminants. The study was conducted at the Food Technology Unit / UTAL and Laboratory of Pathology, Federal University of Acre / UFAC. The samples were submitted to microbiological analysis for the determination of mesophilic bacteria, coliforms at $35{ }^{\circ} \mathrm{C}$ and $45{ }^{\circ} \mathrm{C}$, yeasts and molds, and the second Vanderzant Splittstoesser (1992). The physical and chemical analysis for determining the moisture content and rancidity almond samples were performed using the procedures contained in the analytical standards of the Institute Adolfo Lutz (1985). The counts of coliforms at $45^{\circ} \mathrm{C}$ ranged from <3 to $93 \mathrm{MPN} / \mathrm{g}$ for the Mark 1 and <3 to $240 \mathrm{MPN} / \mathrm{g}$ for the Mark 2. For total coliforms, the results ranged from <3 to $240 \mathrm{MPN} / \mathrm{g}$ for the Mark 1 and <3 to $21 \mathrm{MPN} / \mathrm{g}$ for the Mark 2. The mesophilic bacteria counts ranged from 0.1 to $2.2 \times 103$ to $x 103$ and a mark of 0.0004 to 1.7 x103 x103 for Brand 2. Molds and yeasts ranged from 0.009 to Make a x103 and $<3.0 \times 103$ to $5 \times 103$ for Brand 2. The nuts of the Brazil nuts showed levels of contamination of coliforms at $45^{\circ} \mathrm{C}$ within the standards of the legislation. The microorganisms, mesophilic bacteria, molds, yeasts and coliforms indicate failures in the processing, signaling inadequate hygiene. The positive results of rancidity in some samples indicate failure of the system packaging and storage of products.
\end{abstract}

Key-words: almond chestnut-of-Brazil, coliforms, rancidity.

\title{
Referências
}

BRASIL, Ministério da Saúde Agência Nacional de Vigilância Sanitária de Alimentos, ANVISA. RDC N¹2 DE 02 DE JANEIRO DE 2001. Aprova os padrões microbiológicos para produtos destinados ao consumo. Diário Oficial, DF. 02 de fev. 2001, Seção 1.

COSTA, S. P. E. Microbiota fúngica e espécies produtores de aflatoxinas, ocratoxinas e citrinina em castanha-dobrasil, Bertholletia excelsa Humboldt e Bompland. Dissertaçao de Mestrado em Criptógamas. Universidade Federal de Pernambuco, Recife, 1991.

DONADIO, L. C. ; MÔRO, F. V. ; SERVIDONE, A. A. Frutas Nativas. São Paulo: Editora Novos Talentos, 2002.

HOMMA, A. K. P. O. Cemitério das castanheiras. Ciência Hoje. v. 34, n. 202, março de 2004.

IAL - INSTITUTO ADOLF LUTZ. Normas analíticas do Instituto Adolf Lutz. v.1. Métodos químicos e físicos para analises de alimentos. 3 ed. São Paulo: USP. 1985.

SOUZA, A. H. Castanha-do-pará: estudo botânico, químico e tecnológico. Rio de Janeiro, SAI, 1963. 69p. (SAI estudos técnicos,23). 
SOUZA, M. L. Estudos de processos tecnológicos para a obtenção de produtos derivados de castanha-do-brasil (Bertholletia excelsa, H. B. K.). Dissertação de Mestrado, Universidade Federal do Ceará, Fortaleza, 1984, 139p.

SOUZA, C. J.; LEITE, M. N. Qualidade microbiológica da castanha-do-brasil durante seu processamento e recomendações de boas práticas de fabricação. Monografia do Curso em Tecnologia de Alimentos. Curso de Especialização. Rio Branco: Universidade Federal do Acre, 2002.

SOUZA, M L. Processsamento de cereais matinais extrusados de castanha-do-brasil com mandioca. Tese de doutorado. Campinas: Faculdade de Engenharia de Alimentos, Universidade Federal de Campinas, 2003.

VANDERZANT, C; SPLITTSTOESSER, D. F. Compendium of methods for the microbiological. Examination and Food. American Public Health Association, 1992.

Submetido em 22 jun. 2011; Revisão submetida pelos autores em 31 nov. 2011; Aceito para publicação em 09 dez.2011. 